\title{
A Crystallized Treatise on Determinants of Motivational Environment in Oil and Natural Gas Corporation Limited (ONGC)
}

\author{
Venkata Naga Siva Kumar Challa* Parimi S V Padmalatha Vamsi Krishna Burra \\ Department of Management Studies, Ramachandra College of Engineering \\ Vatluru, Andhra Pradesh, India \\ * E-mail of the corresponding author: challasivakumar2000@gmail.com
}

\begin{abstract}
Technologies have become stakes and those companies who can turn strategy into action at jet speed can bring seamless changes in the organization. In this context motivation has become an important HR intervention in making human resources effective. Companies realized the importance of the motivation as the contribution of employees directly relates their vision and mission statements. Demotivated workforce can cause havoc in failing to meet the organizational objectives. It has the role to develop and intensify the desire of every member of the organization to work effectively and efficiently in their roles. After employees are hired and trained, it is important to motivate them to get the desired efforts from them, to achieve organizational objectives. Owing to the stiff competition among the Multi Nationals in retaining them has become challenge, this paper focus on motivating the workforce by introducing various HR Interventions to motivate and retain for the benefit of the organizational objectives. For this cause a range of motivational factors were considered for a critical assessment on motivational environment in ONGC.
\end{abstract}

Keywords: Motivation, technology, environment, organizational objectives, workforce

DOI: $10.7176 / \mathrm{EJBM} / 13-11-03$

Publication date:June $30^{\text {th }} 2021$

\subsection{Introduction}

Motivation is a critical element in the success of every enterprise. Each company requires motivated workers to maintain its organizational health. This is because engaged workers contribute to the success of companies by becoming more active (Almacik et al., 2012). Thus, engaged workers may lead to an organization's increased value and profitability (McKenzie-Mohr \& Schultz, 2014).

A motivated and trained workforce is critical for increasing corporate efficiency and service quality in order to accomplish organizational goals. For several administrators, the question and problem is how to foster this kind of inspiration. Although there are several hypotheses about motivation, two different fields of motivation are often combined. That is the focus put on job-related encouragement and performance motivation. All are important, and administrators must evaluate the effect of their actions in both areas objectively (Dieleman and Toonen, 2006).

Motivation is critical since even individuals who possess the necessary expertise, talents, and skills can perform poorly if they are not willing to dedicate their time and effort to work (Milapo, 2001). Determining and comprehending the reasons that inspire workers is critical, since every organization's success is contingent upon the presence of a happy and empowered workforce.

The reasons for the above deterioration attributed to the inability of the management to assess and measure the motivational aspects of the employees. The Company human resource (HR) policies are traditional in nature and they could not gauge the changes happening around the world. By the time it realized, changes have already been taken place and been waiting in the form of challenges at the doorsteps of the company. The Company HR policies continuously misjudged the effect of these challenges and are focused on narrow motivational policies, mainly increasing the incentives, pay packages, promotions etc. and these benefits were never connected to the performance of the employees.

\subsection{Literature Review}

They are cognitive decisions, methods, and hypotheses (Campbell et al., 1970) that investigate the motivation system and are driven by Vroom's principle of anticipation, according to Kanfer's (1990) taxonomy of motivation theories (1964). They all described motivation as a mechanism that encourages a person to exert voluntary effort in his or her work (Campbell \& Pritchard, 1976; Graen, 1969; Lawler, 1964). Meanwhile, some scholars contend that the primary emotional states are fundamentally motivational (Izard, 1993), and that they have a tendency to behave or a readiness to act (Fredrickson, 2001; Watson, Wiese, Vaidya, \& Tellegen, 1999). According to Blau (1964), it is focused on social interaction and reciprocity (Gouldner, 1960). To put it another way, emotional organizational engagement can be seen as a trade-off of allegiance and initiative in return for financial gain and social benefits (Eisenberger, Fasolo, \& Davis-LaMastro, 1990). Thus, inspiration is a dynamic process that assists 
someone in achieving a goal (Chowdhury, 2007).

Further discussing the above ideas, Liberman's hypothesis, as expanded by Van Dijk and Kluger (2004), states that individuals are influenced by intrinsic and extrinsic motivations, with both of these two motivations exhibiting distinct characteristics. However, motives can be classified into two additional categories: (a) implicit motives or hidden motives, which are conceptualized as associated networks connecting situational suggestions with fundamental affective reactions and implicit behavioral trends (McClelland, Atkinson, Clark, \& Lowell, 1953); and (b) explicit motives, which are explicit motives to avoid confusion about methods for determining o (Rokeach, 1973). According to Zaltman and Duncan (1977), misunderstandings often arise as a result of a lack of knowledge of personnel demands and capacities for transition adaptation. No agreement is reached with workers on the scope and significance of improvements. Employees, their job climate, traditions, standards, and customs are often disregarded and disregarded.

\subsection{Research Questions}

$>$ Do the theories of motivation applicable to the present context if not what would be the course of action or what would the correct and ideal model to ONGC?

$>$ Does an effective motivational tool transform the entire work force into a dynamic force of commitment and dedication that would lead towards achieving the organizational goals?

$>$ To what extent does motivation remind every employee of their duties responsibilities and make them to sacrifice towards organization and thereby to the society?

\subsection{Objectives of the Study}

1. To evaluate and review the rationale of the changes in the process of the motivation in ONGC.

2. To analyze critical aspects of different methods and techniques adopted by the management to motivate the employees.

3. To explore and identify the key factors responsible for failure of the present policies and how they are unable to achieve the goals enunciated by the top management.

4. To suggest ONGC the measures that motivate the employees for organizational growth and prosperity.

\subsection{Hypotheses}

$>$ There is no significant relationship among average scores of motivations and the factors of motivation.

$>$ There is no significant relationship between motivational environment and the factors of motivation.

$>$ There is no significant relationship between different sub variables of motivation and the factors of motivation.

\subsection{Research Design:}

The study deals with systematic methodology comprising of universe and sample, sources of data collection, study instruments, data processing techniques, presentation and limitations of the study.

The study was conducted in Oil and Natural Gas Limited (ONGC). There are four regions in ONGC namely Eastern, Western, Southern and North region. Out of these four regions $50 \%$ of the regions were selected randomly, that is, two regions. The regions selected for the study are the Western and Southern regions. The number of Executives and Supervisors existing in the two regions Western and Southern, are 6008 and 2705 respectively which constitute to 8713 . Out of these 8713 employees in these two regions together, only, $10 \%$ of them were collected using systematic random sampling from the list of employees available. The list was taken as sampling frame and which comes to 871 .

The questionnaires were distributed to 871 selected employees. The researcher has personally collected the questionnaire from the employees. Irrespective of personal care of the researcher, a number of non-respondents were observed. In addition to these non-respondents, on further scrutiny the questionnaires obtained are found to be incomplete, inconsistent and hence, they were discarded. The total number of complete and consistent questionnaires was found to be 740 .

The significance values have been sought using Chi-Square Analysis, Analysis of Variance (ANOVA) and Paired t- test which would be apt to the study

\subsection{Results and Discussion}

Equivalence and Difference among Different Motivational Factors:

To know the opinions of the respondents whether there exists any equivalence among Motivational factors, one-way Analysis of Variance (ANOVA) was applied to the average scores obtained from the respondents on different Motivational Factors. The null hypothesis is that there is no significant variation among average scores of different motivational factors.

For the average scores obtained for different Motivational factors, the ANOVA table given in Table 1 was 
obtained.

\section{Table No. 1}

ANOVA TABLE (Motivational Factors)

\begin{tabular}{|l|l|l|l|l|l|l|}
\hline Source of Variation & SS & df & MS & F & P-value & F crit \\
\hline Between Groups & 1240.428 & 13 & 95.41757 & 99.04437 & $1.6 \mathrm{E}-251$ & 1.721101 \\
\hline Within Groups & 9967.151 & 10346 & 0.963382 & & & \\
\hline Total & 11207.58 & 10359 & & & & \\
\hline
\end{tabular}

From table 1 it can be inferred that, the null hypothesis that there is no significant variation between average scores of motivational factors is rejected as $p$ value is $1.6 \mathrm{E}-251$. That is there is a significant variation among different motivational factors as far as the average scores are concerned. Hence it can be said that the average scores obtained from the respondents on motivational factors are varying from each other. To assess which pair of competencies showing the same average scores and which one pair is significantly different, further analysis for difference of means between two variables is applied for different possible pairs. The statistical test that was used to test the statistical difference between average scores, a paired t-test for each pair of the average scores of motivational factors is being applied. As there are 14 motivational factors, there will be Ninety-one such pairs that can be obtained.

\section{Paired Samples Test}

Table No. 2

\begin{tabular}{|c|c|c|c|c|c|c|c|}
\hline Sr No. & Pairs of Motivational factors & Mean & $\begin{array}{c}\text { Std. } \\
\text { Deviation }\end{array}$ & $\begin{array}{l}\text { Std. Error } \\
\text { Mean }\end{array}$ & t & df & $\begin{array}{l}\text { Sig. (2- } \\
\text { tailed) }\end{array}$ \\
\hline 1 & Career Growth - Need for Power & -0.16802 & 0.9294 & 0.03417 & -4.918 & 739 & 0 \\
\hline 2 & Career Growth - Transfer and Promotion & 0.35014 & 0.92979 & 0.03418 & 10.244 & 739 & 0 \\
\hline 3 & Career Growth - Learning Aptitude & 0.29527 & 1.20217 & 0.04419 & 6.681 & 739 & 0 \\
\hline 4 & Career Growth - Learning Environment & 0.46554 & 1.25583 & 0.04617 & 10.084 & 739 & 0 \\
\hline 5 & Career Growth - Employee Involvement & -0.18739 & 1.01649 & 0.03737 & -5.015 & 739 & 0 \\
\hline 6 & Career Growth - Recognition & 0.04572 & 0.94112 & 0.0346 & 1.322 & 739 & 0.187 \\
\hline 7 & Career Growth - Achievement & 0.08784 & 1.03985 & 0.03823 & 2.298 & 739 & 0.022 \\
\hline 8 & Career Growth - Affiliation & -0.64892 & 1.03675 & 0.03811 & -17.027 & 739 & 0 \\
\hline 9 & Career Growth - Rewards & 0.19514 & 1.03374 & 0.038 & 5.135 & 739 & 0 \\
\hline 10 & Career Growth - Self Actualization & -0.71622 & 1.31377 & 0.0483 & -14.83 & 739 & 0 \\
\hline 11 & Career Growth - Competence Assessment & 0.37732 & 0.93118 & 0.03423 & 11.023 & 739 & 0 \\
\hline 12 & Career Growth - Self Assessment & -0.23297 & 1.09158 & 0.04013 & -5.806 & 739 & 0 \\
\hline 13 & Career Growth - Interpersonal Relations & -0.11042 & 0.96683 & 0.03554 & -3.107 & 739 & 0.002 \\
\hline 14 & Need for Power - Transfer and Promotion & 0.51815 & 0.93746 & 0.03446 & 15.036 & 739 & 0 \\
\hline 15 & Need for Power - Learning Aptitude & 0.46329 & 1.19673 & 0.04399 & 10.531 & 739 & 0 \\
\hline 16 & Need for Power - Learning Environment & 0.63356 & 1.24972 & 0.04594 & 13.791 & 739 & 0 \\
\hline 17 & Need for Power - Employee Involvement & -0.01937 & 1.00775 & 0.03705 & -0.523 & 739 & 0.601 \\
\hline 18 & Need for Power - Recognition & 0.21374 & 0.92855 & 0.03413 & 6.262 & 739 & 0 \\
\hline 19 & Need for Power - Achievement & 0.25586 & 1.04723 & 0.0385 & 6.646 & 739 & 0 \\
\hline 20 & Need for Power - Affiliation & -0.4809 & 0.9155 & 0.03365 & -14.289 & 739 & 0 \\
\hline 21 & Need for Power - Rewards & 0.36315 & 1.0155 & 0.03733 & 9.728 & 739 & 0 \\
\hline 22 & Need for Power - Self Actualization & -0.5482 & 1.20388 & 0.04426 & -12.387 & 739 & 0 \\
\hline 23 & Need for Power - Competence Assessment & 0.54533 & 0.9274 & 0.03409 & 15.996 & 739 & 0 \\
\hline 24 & Need for Power - Self Assessment & -0.06495 & 1.05709 & 0.03886 & -1.672 & 739 & 0.095 \\
\hline 25 & Need for Power - Interpersonal Relations & 0.05759 & 0.92934 & 0.03416 & 1.686 & 739 & 0.092 \\
\hline
\end{tabular}

Table No. 3

\begin{tabular}{|c|c|c|c|c|c|c|c|}
\hline Sr No. & Pairs of Motivational factors & Mean & Std. Deviation & Std. Error Mean & t & df & Sig. (2-tailed) \\
\hline 1 & Transfer and Promotion - Learning Aptitude & -0.05486 & 1.02656 & 0.03774 & -1.454 & 739 & 0.146 \\
\hline 2 & Transfer and Promotion - Learning Environment & 0.11541 & 1.05354 & 0.03873 & 2.98 & 739 & 0.003 \\
\hline 3 & Transfer and Promotion- Employee Involvement & -0.53752 & 0.98675 & 0.03627 & -14.819 & 739 & 0 \\
\hline 4 & Transfer and Promotion - Recognition & -0.30441 & 0.84888 & 0.03121 & -9.755 & 739 & 0 \\
\hline 5 & Transfer and Promotion - Achievement & -0.2623 & 0.94648 & 0.03479 & -7.539 & 739 & 0 \\
\hline 6 & Transfer and Promotion - Affiliation & -0.99905 & 0.93063 & 0.03421 & -29.203 & 739 & 0 \\
\hline 7 & Transfer and Promotion - Rewards & -0.155 & 0.84143 & 0.03093 & -5.011 & 739 & 0 \\
\hline 8 & Transfer and Promotion - Self Actualization & -1.06635 & 1.22662 & 0.04509 & -23.649 & 739 & 0 \\
\hline 9 & Transfer and Promotion Competence Assessment & 0.02718 & 0.71716 & 0.02636 & 1.031 & 739 & 0.303 \\
\hline 10 & Transfer and Promotion - Self Assessment & -0.58311 & 0.92491 & & 0.034 & -17.15 & 739 \\
\hline
\end{tabular}




\begin{tabular}{|c|c|c|c|c|c|c|c|}
\hline Sr No. & Pairs of Motivational factors & Mean & Std. Deviation & Std. Error Mean & t & df & Sig. (2-tailed) \\
\hline 11 & Transfer and Promotion - Interpersonal Relations & -0.46056 & 0.86211 & 0.03169 & -14.532 & 739 & 0 \\
\hline 12 & Learning Aptitude - Learning Environment & 0.17027 & 1.14423 & 0.04206 & 4.048 & 739 & 0 \\
\hline 13 & Learning Aptitude - Employee Involvement & -0.48266 & 1.15608 & 0.0425 & -11.357 & 739 & 0 \\
\hline 14 & Learning Aptitude - Recognition & -0.24955 & 1.09201 & 0.04014 & -6.216 & 739 & 0 \\
\hline 15 & Learning Aptitude - Achievement & -0.20743 & 1.12383 & 0.04131 & -5.021 & 739 & 0 \\
\hline 16 & Learning Aptitude - Affiliation & -0.94419 & 1.12634 & 0.04141 & -22.804 & 739 & 0 \\
\hline 17 & Learning Aptitude - Rewards & -0.10014 & 1.01596 & 0.03735 & -2.681 & 739 & 0.007 \\
\hline 18 & Learning Aptitude - Self Actualization & -1.01149 & 1.32206 & 0.0486 & -20.813 & 739 & 0 \\
\hline 19 & Learning Aptitude - Competence Assessment & 0.08205 & 0.94012 & 0.03456 & 2.374 & 739 & 0.018 \\
\hline 20 & Learning Aptitude - Self Assessment & -0.52824 & 1.06415 & 0.03912 & -13.503 & 739 & 0 \\
\hline 21 & Learning Aptitude - Interpersonal Relations & -0.40569 & 1.07099 & 0.03937 & -10.305 & 739 & 0 \\
\hline 22 & Learning Environment - Employee Involvement & -0.65293 & 1.22867 & 0.04517 & -14.456 & 739 & 0 \\
\hline 23 & Learning Environment - Recognition & -0.41982 & 1.15767 & 0.04256 & -9.865 & 739 & 0 \\
\hline 24 & Learning Environment - Achievement & -0.3777 & 1.17328 & 0.04313 & -8.757 & 739 & 0 \\
\hline
\end{tabular}

Table No. 4

\begin{tabular}{|c|c|c|c|c|c|c|c|}
\hline Sr No. & Pairs of Motivational factors & Mean & Std. Deviation & Std. Error Mean & $\mathrm{t}$ & $\mathrm{Df}$ & Sig. (2-tailed) \\
\hline 1 & Employee Involvement - Recognition & 0.23311 & 0.81187 & 0.02984 & 7.811 & 739 & 0 \\
\hline 2 & Employee Involvement - Achievement & 0.27523 & 0.96772 & 0.03557 & 7.737 & 739 & 0 \\
\hline 3 & Employee Involvement - Affiliation & -0.46153 & 0.90205 & 0.03316 & -13.918 & 739 & 0 \\
\hline 4 & Employee Involvement - Rewards & 0.38252 & 1.07295 & 0.03944 & 9.698 & 739 & 0 \\
\hline 5 & Employee Involvement - Self Actualization & -0.52883 & 1.2556 & 0.04616 & -11.457 & 739 & 0 \\
\hline 6 & Employee Involvement - Competence Assessment & 0.5647 & 0.96039 & 0.0353 & 15.995 & 739 & 0 \\
\hline 7 & Employee Involvement - Self Assessment & -0.04559 & 1.08156 & 0.03976 & -1.147 & 739 & 0.252 \\
\hline 8 & Employee Involvement - Interpersonal Relations & 0.07696 & 0.88331 & 0.03247 & 2.37 & 739 & 0.018 \\
\hline 9 & Recognition - Achievement & 0.04212 & 0.78466 & 0.02884 & 1.46 & 739 & 0.145 \\
\hline 10 & Recognition - Affiliation & -0.69464 & 0.9265 & 0.03406 & -20.395 & 739 & 0 \\
\hline 11 & Recognition - Rewards & 0.14941 & 0.99566 & 0.0366 & 4.082 & 739 & 0 \\
\hline 12 & Recognition - Self Actualization & -0.76194 & 1.31375 & 0.04829 & -15.777 & 739 & 0 \\
\hline 13 & Recognition - Competence Assessment & 0.3316 & 0.81774 & 0.03006 & 11.031 & 739 & 0 \\
\hline 14 & Recognition - Self Assessment & -0.27869 & 1.08486 & 0.03988 & -6.988 & 739 & 0 \\
\hline 15 & Recognition - Interpersonal Relations & -0.15615 & 0.81785 & 0.03006 & -5.194 & 739 & 0 \\
\hline 16 & Achievement - Affiliation & -0.73676 & 0.94907 & 0.03489 & -21.117 & 739 & 0 \\
\hline 17 & Achievement - Rewards & 0.1073 & 0.92495 & 0.034 & 3.156 & 739 & 0.002 \\
\hline 18 & Achievement - Self Actualization & -0.80405 & 1.31935 & 0.0485 & -16.578 & 739 & 0 \\
\hline 19 & Achievement - Competence Assessment & 0.28948 & 0.86168 & 0.03168 & 9.139 & 739 & 0 \\
\hline 20 & Achievement - Self Assessment & -0.32081 & 1.0325 & 0.03796 & -8.452 & 739 & 0 \\
\hline 21 & Achievement - Interpersonal Relations & -0.19826 & 0.92248 & 0.03391 & -5.847 & 739 & 0 \\
\hline 22 & Affiliation - Rewards & 0.84405 & 0.9347 & 0.03436 & 24.565 & 739 & 0 \\
\hline 23 & Affiliation - Self Actualization & -0.0673 & 1.06165 & 0.03903 & -1.724 & 739 & 0.085 \\
\hline 24 & Affiliation - Competence Assessment & 1.02624 & 0.85192 & 0.03132 & 32.769 & 739 & 0 \\
\hline 25 & Affiliation - Self Assessment & 0.41595 & 0.84796 & 0.03117 & 13.344 & 739 & 0 \\
\hline 26 & Affiliation - Interpersonal Relations & 0.53849 & 0.85603 & 0.03147 & 17.112 & 739 & 0 \\
\hline 27 & Rewards - Self Actualization & -0.91135 & 1.1438 & 0.04205 & -21.675 & 739 & 0 \\
\hline 28 & Rewards - Competence Assessment & 0.18218 & 0.7778 & 0.02859 & 6.372 & 739 & 0 \\
\hline 29 & Rewards - Self Assessment & -0.42811 & 0.90733 & 0.03335 & -12.835 & 739 & 0 \\
\hline 30 & Rewards - Interpersonal Relations & -0.30556 & 0.92971 & 0.03418 & -8.941 & 739 & 0 \\
\hline 31 & Self-Actualization - Competence Assessment & 1.09353 & 1.19813 & 0.04404 & 24.828 & 739 & 0 \\
\hline 32 & Self-Actualization - Self Assessment & 0.48324 & 1.12782 & 0.04146 & 11.656 & 739 & 0 \\
\hline 33 & Self-Actualization - Interpersonal Relations & 0.60579 & 1.17893 & 0.04334 & 13.978 & 739 & 0 \\
\hline 34 & Competence Assessment - Self Assessment & -0.61029 & 0.86889 & 0.03194 & -19.107 & 739 & 0 \\
\hline 35 & Competence Assessment - Interpersonal Relations & -0.48774 & 0.78292 & 0.02878 & -16.947 & 739 & 0 \\
\hline 36 & Self-Assessment - Interpersonal Relations & 0.12255 & 0.91433 & 0.03361 & 3.646 & 739 & 0 \\
\hline
\end{tabular}

From the tables 2 to 4 , it is inferred that Career Growth is significantly different from the other factors namely, Need for Power, Transfer and Promotion, Learning Aptitude, Learning Environment, Employee Involvement, Achievement, Affiliation, Rewards, Self-actualization, Competence Assessment, Self-assessment and 
Interpersonal Relations whereas, there is no significant difference between Career Growth and Recognition. It is also to infer that the average scores of Career Growth is greater than Transfer and Promotion, Learning Aptitude, Learning Environment, Achievement, Rewards and Competence Assessment. In all other cases, the average scores of Career Growth is less than the others.

It is inferred that Need for Power is significantly different from the other factors namely, Transfer and Promotion, Learning Aptitude, Learning Environment, Recognition, Achievement, Affiliation, Rewards, Selfactualization and Competence Assessment whereas, there is no significant difference between Need for Power and Employee Involvement, Self-Assessment and Interpersonal Relations. It is also to infer that the average scores of Need for Power is greater than Transfer and Promotion, Learning Aptitude, Learning Environment, Recognition, Achievement, Rewards and Competence Assessment. In the remaining three cases where significant difference is inferred average scores of Needs for Power is less.

The motivational factor, Transfer and Promotion is significant different from the other factors namely, Learning Environment, Employee Involvement, Recognition, Achievement, Affiliation, Rewards, Selfactualization, Self-Assessment and Interpersonal Relations whereas, there is no significant difference between Learning Aptitude and Competence Assessment. The average score of Transfer and Promotion is more than average score of Learning Environment and Competence Assessment only. In case of the remaining factors average score of transfer and promotion is less.

The motivational factor, Learning Aptitude is significantly different from the other factors namely, Learning Environment, Employee Involvement, Recognition, Achievement, Affiliation, Rewards, Self-actualization, Competence Assessment, Self- Assessment and Interpersonal Relations. The average score of learning aptitude is more than the average scores of Learning Environment and Competence Assessment only. In case of the remaining factors the average scores of learning aptitude is comparatively less than the others.

The motivational factor, Learning Environment is significantly different from the factors namely, Employee Involvement, Recognition, Achievement, Affiliation, Rewards, Self-actualization, Competence Assessment, SelfAssessment and Interpersonal Relations. The average score of Learning Environment is less than the average scores of other factors namely, Employee Involvement, Recognition, Achievement, Affiliation, Rewards, SelfActualization, Competence Assessment, Self- Assessment and Interpersonal Relations.

The motivational factor, Employee Involvement is significantly different from the factors namely, Recognition, Achievement, Affiliation, Rewards, Self-actualization, Competence Assessment, Self-Assessment and Interpersonal Relations. Whereas, Employee Involvement is not showing in a significant difference with selfassessment. The average score of Employee Involvement is more than the average scores of Recognitions, Achievement, Rewards, Competence Assessment and Interpersonal Relations. The average score of Employee Involvement is less than averages scores of Affiliations, Self-actualization and Self-Assessment.

The motivational factor, Recognition is significantly different from the factors namely, Affiliation, Rewards, Self-actualization, Competence Assessment, Self-Assessment and Interpersonal Relations. Whereas, Recognition is not showing any significant difference with Achievement. The average score of Recognition is more than the average scores of Achievements, Rewards and Competence Assessment. The average score of Recognition is less than averages scores of Affiliation, Self-actualization, Self-Assessment and Interpersonal Relations.

The motivational factor, Achievement is significantly different from the factors namely, Affiliation, Rewards, Self-actualization, Competence Assessment, Self-Assessment and Interpersonal Relations. The average score of Achievement is more than the average scores of Rewards and Competence Assessment. The average score of Achievement is less than averages scores of Affiliation, Self-actualization, Self-Assessment and Interpersonal Relations.

The motivational factor, Affiliation is significantly different from the factors namely, Rewards, Competence Assessment, Self-Assessment and Interpersonal Relations. Whereas, the Affiliation is not significantly different with Self-Actualization. The average score of Affiliation is more than the average scores of Rewards, Competence Assessment, Self-Assessment and Interpersonal Assessment. The average score of Affiliation is less than the averages scores of Self-actualization Only.

The motivational factor, Rewards are significantly different from the other factors namely, Self-Actualization, Competence Assessment, Self-Assessment and Interpersonal Relations. The average score of Rewards is more than the average scores of Competence Assessment only. The average score of Rewards is less than the averages scores of Self-actualization, Self-Assessment and Interpersonal Relations.

The motivational factor, Self-Actualization is significantly different from the other factors namely, Competence Assessment, Self-Assessment and Interpersonal Relations. The average score of Self-Actualization is more than the average scores of Competence Assessment, Self-Assessment and Interpersonal Assessment.

The motivational factor, Competence Assessment is significantly different from the other factors namely, Self-Assessment and Interpersonal Relations. The average score of Competence Assessment is less than the average scores of Self-Assessment and Interpersonal Assessment.

The motivational factor, Self-Assessment is significantly different from the parameter Interpersonal Relations. 
The average score of Self-Assessment is more than the average score of Interpersonal Assessment.

Considering the average scores given by the respondents on different motivational factors, it is inferred that the most favored motivational factor by the respondents is Self-Actualization and least favored motivational factor is Learning Environment. The order of the motivational factors according to the level of according to the favorableness by the respondents are Self-Actualization, Affiliation, Self-Assessment, Employee Involvement, Need for Power, Interpersonal Relations, Career Growth, Recognition, Achievement, Rewards, Learning Aptitude, Transfer \& Promotion, Competence Assessment and Learning Environment in descending order.

\subsection{Recommendations}

\section{- Scientific Performance Assessment}

Company's performance appraisal system should be reviewed every year by taking inputs from their employees for more scientific way of assessing the capability of the employees in a scientific manner. The organization may migrate to competence-based approach to performance from trait-result based approach. It is also suggested that it is very essential to assess the performance of the employee vis-à-vis the Cost to the Company. In other words, company should be in a position to assess the employee's contribution on real time basis to know the return on the investment of their employees.

\section{- Gender Policy Changes}

The study suggests a strong relationship between gender and achievement. Therefore, the organization is required to formulate its policy on motivation to derive better achievement. The achievement motive differs between men and women. Equal opportunity for performance may leverage from the benefit of Achievement motive.

\section{- Employee Involvement}

The Location of Unit drives Employee Involvement. This difference across the location of unit is an interesting finding. The difference in the motive of Employee Involvement may be on Age, Experience, Cadre, Grade and Salary. The employment factors are the determinants for this motive. Therefore, the organization can frame a better employee involvement policy with the above employment factors as the criteria. However, the organization may enhance their focus on 'Theory $\mathrm{Y}$ ' category of employees according to Mc Gregor and involve the employees to motivate them better.

- Educational Qualifications Improvement

The Educational Qualification is impacting Reward factor of motivation. The organization can give scope for improving educational qualification. The supervisor cadre consists of promotes without qualifications for designations in Executive cadre. Therefore, integrated policy for improving educational qualifications is required.

\section{- $\quad$ Fast Track promotion}

The cadre is a factor for self-actualization. The Cadre refers to the executives and supervisors. The supervisor cadre is the highest level for the non-qualification holders in workmen cadre. Therefore, promotion channel may be made merit based and experience based separate. The suggestion is two separate promotion channels.

- Experience based promotion.

- Merit Based promotion.

- Employee Realization

The Self-Assessment as a factor is not critical to motivation is the outcome of the study. The SelfAssessment will be realistic if employee realization is high in the Organization. Therefore, it was suggested to implement self-awareness training for the employees to enable them to accurately evaluate their own Performance - Balance Reward Policy.

- Balanced Reward Policy

The reward as source of Motivation is absolutely absent in the organization. The reward is linked to Grade. The revamping of reward system is major policy-based change suggested based on the outcome of the study.

Over a period of time owing to the work pressures and to reach the targets, top management and senior officers depend on the few who contribute and work hard to finish the jobs given by their superiors. The superior officers do not have time to concentrate on their work force to find out the reasons for nonperformance by some of their subordinates.

- Revamping Welfare Schemes

The Welfare schemes shall be the source of motivation in the organization. As a part of reward, the schemes may be made need based rather than fixed basis. The unfulfilled safety, security, physiological needs to be targeted. The choice-based system for welfare scheme can be framed. 


\subsection{Conclusion}

The subject is approached persuasively by integrating scientific principles and empirical data with an applicationoriented methodology that results in concrete guidance for how to boost motivation. Its objective is to identify theoretical principles and realistic strategies that will assist managers in motivating their workers. A compelling study of the intellectual richness of encouragement that extends far beyond cash rewards is discussed, as well as an impressively broad and succinct description of alternative methods and strategies that can be made accessible to public managers as a tool set.

It provides valuable lessons for professionals and scholars alike and demonstrates how to effectively link public policy science and implementation. The main factors of motivation such as Learning environment, Transfer and promotion, Performance assessment and the like are impacting motivation in ONGC. These factors are to be viewed from the prevailing internal and external economic policies and conditions in India. The conclusion from the study provides a conceptual framework to understand the contemporary motivational environment in Public Sector organizations in India.

\section{References}

1. Alnıaçık, Ü. et.al. (2012). Relationships Between Career Motivation, Affective Commitment and Job Satisfaction. Procedia-Social and Behavioral Sciences, 58, 355-362

2. Blau, P. M. (1964). Exchange and power in social life. New York, NY: John Wiley

3. Campbell, et.al. (1976). Motivation theory in industrial and organizational psychology. In M. Dunnette Ed.), Handbook of industrial and organizational psychology (pp. 63-130). Chicago, IL: Rand-McNally

4. Chowdhury, M. S. (2007). Enhancing motivation and work performance of the salespeople: The impact of supervisors' behavior. African Journal of Business Management, 1, 238-243

5. Dieleman M, et.al. (2006), The match between motivation and performance management of health sector workers in Mali. Human Resource Health. Feb 9; 4:2

6. Eisenberger, R, et.al. (1990). Perceived organizational support and employee diligence, commitment and innovation. Journal of Applied Psychology, 75, 51-59

7. Gouldner, A. W. (1960). The norm of reciprocity. American Sociological Review, 25, 165-167

8. Graen, G. B. (1969). Instrumentality theory of work motivation: Some experimental results and suggested modifications Some experimental results and suggested modifications. Journal of Applied Psychology, 53(2), $1-25$

9. Izard, C. E. (1993). Four systems for emotion activation: Cognitive and non-cognitive processes. Psychological Review, 100, 60-69

10. Kanfer, R. (1990). Motivation theory and industrial and organizational psychology. In M. D. Dunnette \& L. M. Hough (Eds.), Handbook of industrial and organizational psychology (Vol. 1, pp. 75-170). Palo Alto, CA: Consulting Psychologists Press

11. Rokeach, M. (1973). The nature of human values. New York, NY: Free Press

12. Lawler, E. E., III. (1964). Managers' job performance and their attitudes toward their pay (Doctoral dissertation). University of California, Berkeley

13. McKenzie-Mohr, D., \& Schultz, P. W. (2014). Choosing effective behavior change tools. Social Marketing Quarterly, 20(1), 35-46

14. McClelland, et.al. (1953). The achievement motive. Norwalk, CT: Appleton-Century-Croft

15. Milapo, L. T. (2001). 'Performance Enhancement in the Civil Service: A Comparative Analysis of the use of HRM Tools in Uganda, Zambia and Zimbabwe', Master 's Research Paper. Institute of Social Studies, Erasmus University

16. Vroom, V. H. (1964). Work and motivation. New York, NY: John Wiley

17. Watson, D, et.al. (1999). The two general activation systems of affect: Structural findings, evolutionary considerations, and psychobiological evidence. Journal of Personality and Social Psychology, 76, 820-838

18. Zaltman, G., \& Duncan, R. (1977). Strategies for planned change. New York, NY: John Wiley 